\title{
PENDIDIKAN KELUARGA HINDU KONTEMPORER ERA 4.0 DALAM SIAR AGAMA UNTUK MEMBENTUK KARAKTER PADA KELOMPOK SSG PRAYA KABUPATEN LOMBOK TENGAH
}

Oleh:

\author{
L. Eka M. Julianingsih $P$ \\ l.eka.m.j.p.90@gmail.com \\ STAHN Mpu Kuturan Singaraja
}

Proses Review 10 Agustus-2 September, Dinyatakan Lolos 5 September

\begin{abstract}
Hinduism is a very ancient civilization that still lives today, in modern modern times with developments in more advanced civilizations that enhance human thinking and attitudes in everyday life, especially in large cities where society is not in the industry. . Of course this is a challenge for Hindus who practice morality according to the Dharma teachings. Departing from this there are those who issue a problem statement, namely: (1) What is the structure of education carried out by the SSG group in family education? (2) what is the pattern applied by the SSG group in family education? This research is qualitative research with research that proves that (1) the structure of education carried out by the SSG group in family education is carried out by giving challenging dharma teachings, namely: Dharma gita, Dharma Wacana, Dharma tula, Dharma Sadhana, Dharma Yatra, Dharma Santi to form characters. (2) Patterns applied: the closeness of the relationship between parents and children, parental responsibility for children, a comfortable home environment and good children's achievement
\end{abstract}

Keywords: family education contemporary era 4.0, religious broadcasting of Hinduism

\section{Abstrak}

Agama Hindu adalah peradaban yang sangat kuno yang masih hidup hingga saat ini, di zaman modern, dengan perkembangan peradaban yang lebih maju yang meningkatkan pemikiran dan sikap manusia dalam kehidupan sehari-hari, terutama di kota-kota besar dimana masyarakat tidak berada dalam industri. . Tentu hal ini menjadi tantangan bagi umat Hindu yang mengamalkan akhlak sesuai dengan ajaran Dharma. Berangkat dari hal tersebut penelitian ini membedah tiga permasalahan, yaitu (1) Bagaimana struktur pendidikan yang dilakukan oleh kelompok SSG dalam pendidikan keluarga? (2) Bagaimana pola yang diterapkan kelompok SSG dalam pendidikan keluarga? Penelitian ini merupakan penelitian kualitatif dengan penelitian yang membuktikan bahwa (1) struktur pendidikan yang dilaksanakan oleh kelompok SSG dalam pendidikan keluarga dilaksanakan dengan memberikan ajaran dharma yang menantang, yaitu: Dharma gita, Dharma Wacana, Dharma tula, Dharma Sadhana, Dharma Yatra, Dharma Santi untuk membentuk karakter. 
(2) Pola yang diterapkan: kedekatan hubungan antara orang tua dan anak, tanggung jawab orang tua terhadap anak, lingkungan rumah yang nyaman dan prestasi anak yang baik.

Kata kunci: pendidikan keluarga era kontemporer 4.0, penyiaran agama Hindu

\section{PENDAHULUAN}

Pembangunan nasional di bidang pendidikan adalah upaya mencerdaskan kehidupan bangsa dan meningkatkan kualitas manusia Indonesia dalam mewujudkan masyarakat yang maju, adil, dan makmur berdasarkan Pancasila dan Undang-Undang Dasar 1945. Hal tersebut dapat dijadikan sebagai dasar pembangunan manusia Indonesia seutuhnya. Oleh karena itu pendidikan sangat penting baik bagi kepentingan umum maupun pribadi.

Begitu pentingnya pendidikan untuk kemajuan dan kelangsungan hidup manusia sehingga tindakan yang dilakukan setiap orang tanpa disadari merupakan hasil dari proses pendidikan. Menurut Undang-Undang RI No. 20 tahun 2003 tentang Sistem Pendidikan Nasional, pendidikan adalah usaha sadar dan terencana untuk mewujudkan suasana belajar dan proses pembelajaran agar peserta didik secara aktif mengembangkan potensi dirinya untuk memiliki kekuatan spiritual keagamaan, pengendalian diri, kepribadian, kecerdasan, akhlak mulia, serta keterampilan yang diperlukan dirinya, masyarakat, bangsa dan Negara, sehingga pendidikan dapat menjadi salah satu penentu utama bagi kemajuan suatu bangsa. Dengan adanya pendidikan maka sumber daya manusia yang dihasilkan akan memiliki kualitas yang baik sebagai penggerak pembangunan bangsa, oleh karena itu seluruh anggota masyarakat hendaknya harus menyelesaikan pendidikan untuk dapat mengembangkan potensi dirinya.

Untuk menjadikan Indonesia sebagai negara maju yang bermoral tinggi, sangat diperlukan sekali adanya proses pendidikan baik bersifat formal maupun non formal. Pendidikan non formal, misalnya pendidikan keluarga. Didalam pendidikan keluarga, orang tua merupakan pendidik pertama dan utama dalam pembentukan karakter anak. Proses kehidupan didalam sebuah keluarga adalah proses belajar pertama bagi anak sebelum mereka hidup dalam lingkungan yang lebih luas yaitu sekolah dan masyarakat. Oleh karena itu seharusnya setiap orang tua harus mampu memanfaatkan masa ini untuk mengembangkan potensi anak, sehingga anak dapat berkembang menjadi seorang anak yang suputra terutama di era 4.0" yang di tandai dengan perkembangan industry yang begitu pesat yang menjadikan manusia sangat tergantung dengan hal-hal yang bersifat sains. Menurut Syamsuar, (2018) Kebijakan manajemen pendidikan di Indonesia saat ini mendorong seluruh level pendidikan, terutama pendidikan tinggi untuk memanfaatkan kemajuan teknologi digital dan komputerisasi pendidikan era revolusi industry keempat.

Di era revolusi industry 4.0 pendidikan agama memegang andil yang tidak kecil dalam rangka mencapai tujuan pendidikan nasional, pada pasal 1 ayat 1 Undang-Undang Sistem Pendidikan Nasional Nomor 20 Tahun 2003 menjelaskan bahwa ada empat komponen tujuan pendidikan yang pencapaiannya menjadi beban pendidikan agama, yaitu memiliki kekuatan spiritual keagamaan, pengendalian diri, kepribadian dan akhlak mulia. Sehingga pendidikan agama memiliki peranan besar dalam membina moralitas bangsa, terlebih dengan banyaknya berita-berita yang melenceng dari norma agama yang sarat akan degradasi moral seperti kasus pembunuhan, makar, hoak dan hal-hal lainnya.

Untuk mengantisipasi degradasi moral yang kian terjadi, terdapat sekelompok orang membentuk kelompok spiritual bertempat di wilayah Praya, Kabupaten Lombok Tengah dengan tujuan untuk membentuk karakter diri. Hal ini sesuai dengan VISI dari SSG itu sendiri yaitu menyadari KeTuhanan yang menyatu di dalam diri manusia (Aham Brahmana Asmi). Hal ini berarti ketika seseorang mampu menyadari KeTuhanan di dalam dirinyalah, saat itu barulah ia melihat esensi KeTuhanan yang sama di dalam hati setiap mahluk. Dengan demikian 
seseorang harus saling mengasihi dan melakukan perbuatan yang baik. Seperti yang tertuang dalam kitab Sārasamuccaya Sloka 2 sebagai berikut :

"Ri sakwehning sarwa bhuta, iking janma wwang juga wênang gumawayaken ikang subhāsubha karma, kuneng panêntasakêna ring subhakarma juga ikangaśubhakarma phalaning dadi wwang".

\section{Terjemahan:}

Diantara semua makhluk hidup, hanya yang dilahirkan menjadi manusia sajalah yang dapat melaksanakan perbuatan baik ataupun buruk, leburlah kedalam perbuatan baik segala perbuatan yang buruk itu, demikianlah gunanya (pahalanya) menjadi manusia (Kajeng, dkk, 2003).

Berdasarkan sloka di atas diharapkan melalui pendidikan agama Hindu dapat merubah perilaku seseorang menjadi lebih baik. Hal ini menjadi tantangan tersendiri bagi kelompok Sai Study Grup (SSG) Praya, Kabupaten Lombok Tengah dalam memberikan pendidikan dan penyebaran ajaran agama di keluarganya. Oleh karena itu permasalahan yang diangkat dalam penelitian ini berfokus pada: 1) bagaimana struktur yang dijalankan oleh kelompok SSG di
Era 4.0' didalam memberikan pendidikan Keluarga, 2) bagaimana Pola Yang Diterapkan Kelompok SSG dalam pendidikan Keluarga.

\section{METODE}

Penelitian ini menggunakan pendekatan kualitatif yang dilakukan secara purposif dengan teknik pengumpulan data menggunakan triangulasi. Adapun jenis penelitian yang digunakan adalah jenis studi kasus. Pada penelitian ini, peneliti menggunakan studi kasus tunggal holistik dengan obyek penelitian kelompok SSG Praya Lombok.

\section{PEMBAHASAN}

\section{III.1Stuktur pendidikan yang Dijalankan Oleh Kelompok SSG di Era 4.0 di dalam Pendidikan Keluarga}

Struktur pendidikan yang dijalankan oleh kelompok SSG di dalam pendidikan keluarga adalah menjalankan ajaran sad dharma, dimana sad dharma merupakan enam macam jalan mencapai kebenaran yang dapat dilakukan oleh umat Hindu, diantaranya adalah: Dharma Gita, Dharma Wacana, Dharma Tula, Dharma Sadhana, Dharma Yatra, Darma Santih untuk pencapaian pikiran, perkataan dan tindakan yang sesuai dengan ajaran agama (Tri Kaya Parisudha).

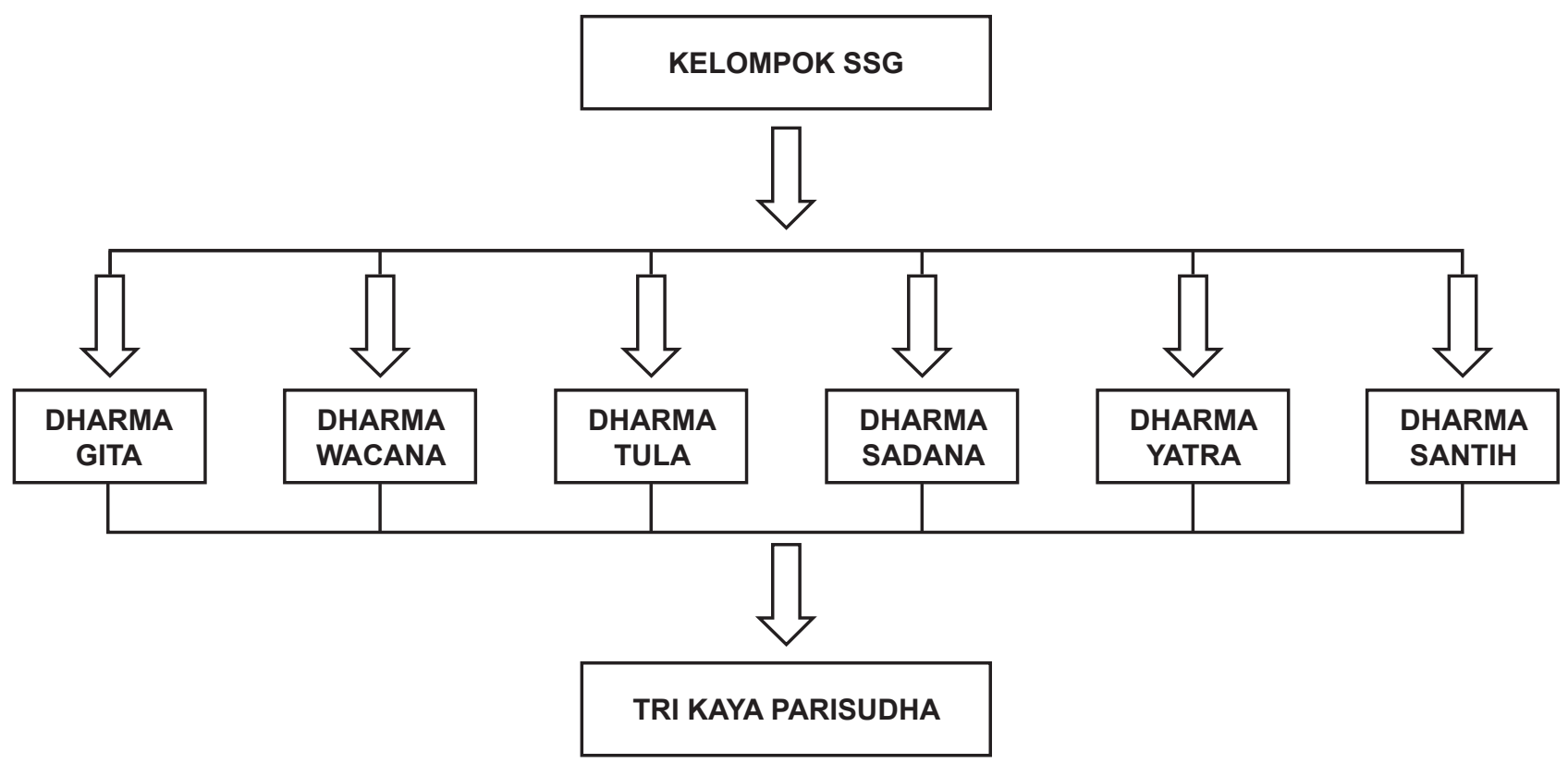




\section{Dharma Gita}

Dharma gita merupakan nyanyiannyanyian kerohanian yang di lagukan dengan penuh penghayatan. Didalam menjalankan pendidikan keluarga oleh kelompok SSG, orang tua selalu mengajak anaknya untuk bersama-sama mengadakan ritual upacara keagamaa. Pada kelompok SSG upacara keagamaan yang dilakukan selain mengikuti purnama, tilem maupun hari suci yang berdasarkan sasih atau pawukon, kelompk ini juga memiliki kegiatan upacara pemujaan wajib dilaksanakan di hari kamis yaitu kegiatan Bhajan. Kegiatan Bhajan ini merupakan kegiatan menyanyikan/ melantunkan lagu-lagu keagungan para dewa, dengan tujuan untuk mencapai anandam (kebahagiaan). Dimana lagu pemujaan yang dilakukan di mulai dengan pemujaan Ganesha. Kemudian dilanjutkan dengan lagu-lagu pujian kepada para dewa dewi yang lainnya. Di era 4.0 ini, semua alat music yang digunakan tidak hanya alat music tradisional saja, namun di kombinasikan antara alat music tradisional dan modern

\section{Dharma Wacana}

Setelah menyanyikan lagu-lagu Bhajan, salah satu anggota kelompok yang sudah ditentukan akan memberikan Dharma Wacana yang sumbernya di ambil dari pustaka suci weda. Tujuan dari dharma wacana ini agar anggota yang lain mendapat pengetahuan mengenai ajaran Sanatana Dharma, yang merupakan inti sari ajaran bagi umat Hindu. Dharma Wacana merupakan metode ceramah dalam bentuk interaksi diantara guru dan sisya melalui proses penerangan atau penuturan secara lisan dari guru kepada sisyanya. Juwita Br Meliala, dkk (2018). Meskipun kegiatan dharma wacana merupakan metoda ortodoks, namun dengan adanya media-media bantu yang digunakan, maka ceramah yang disajikan dapat lebih dipahami oleh para bhaktanya (anggotanya).

\section{Dharma Tula}

Selain memberikan dharma wacana, kelompok SSG juga memiliki agenda wajib yaitu, diadakannya Dharma Tula. Dharma Tula di dalam kelompok SSG dikenal dengan istilah Satsang (diskusi keagamaan). Didalam satsang inilah, segala bentuk permasalahan dibicarakan dan didiskusikan dengan sesama anggota. Dengan rujukan yang selalu bersumber dari pustaka suci weda.

\section{Dharma Sadhana}

Dharma sadana merupakan pemberian yang tulus iklas tanpa pamerih. Dharma sdhana ini juga menjadi kegiatan berkala yang selalu dilakukan oleh SSG Praya. Seperti pengadaan donor darah, pemberian buku tulis bagi anak-anak kecil yang berada di lingkungan sekitar. Dharma Sadhana yang dilakukan oleh orang tua ini bertujuan agar anak-anak dalam kelompok SSG mampu mengikuti dan mencontoh hal-hal baik yang dilakukan oleh orang tua mereka.

\section{Dharma Yatra}

Dharma yatra sering dikenal dengan istilah tirtayatra. Dharma yatra ini merupakan perjaanan dari satu tempat ketempat suci lain guna meningkatkan saradha dan bhakti ke hadapan Ida Sang Hhyang Widhi Wasa. Dharma Yatra ini dilakukan, selain untuk mengagumi kebesaran Tuhan sebagai sang pencipta, tentu saja ini juga dilakukan sebagai ajang refresing keluarga. Menurut Aryanatha, I Nengah (2019) keinginan berwisata (refreshing) bukan sematamata hanya pemenuhan kebutuhan jasmani (kebugaran badan fisik) semata tetapi lebih pada pemenuhan kebutuhan rohani (ketenangan jiwa dan pikiran) ditengah tuntutan pekerjaan dan rutinitas masyarakat modern saat ini. Oleh karena sangat disadari bahwa di dalam menjalin hubungan yang harmonis, tentu saja perlu kedekatan antar anggota keluarga. Dengan 
berpergian ketempat-tempat religious bersama keluarga, maka kedekatan yang diharapkan akan dapat tercapai. Jika di jaman terdahulu, orang melakukan dharma yatra dengan berjalan kaki, namun di era industry dengan teknologi yang canggih seperti sekarang, banyak transportasi yang bisa digunakan untuk mengunjungi tempat-tempat yang diinginkan.

\section{Dharma Santih}

Dharma santih juga dilakukan oleh Kelompok SSG. Dengan waktu bertemu antar keluarga yang teratur, maka antar anggota di kelompok SSG, akan saling memahami satu dengan yang lainnya. Dengan pemahaman yang baik akan perilaku anggota, maka diharapkan akan terjadi kehidupan yang santih.

\section{III.2 Pola Yang Diterapkan Kelompok SSG dalam pendidikan Keluarga}

Pendidik utama dan pertama sebelum anakanak mengenyam pendidikan di bangku sekolah adalah orang tua. Keluarga sebagai lembaga pendidikan memiliki beberapa fungsi, seperti: membentuk kepribadian anak, melaksanakan pedidikan anak di rumah dan mendukung pendidikan di sekolah. Sehingga orang tua yang terlibat aktif dalam penyelenggaraan pendidikan di sekolah akan menciptakan pendidikan yang lebih efektif bagi karakter anak.

\section{Kedekatan Hubungan Orang Tua dan Anak}

Salah satu fondasi penting bagi tumbuh kembang pendidikan anak adalah kedekatan yang terjalin antara orang tua dengan anak. Kedekatan dan cinta kasih orang tua akan dapat mencegah anak melakukan perbuatanperbuatan yang menyimpang, terutama pada masa anak usia remaja yang dapat menyebabkan timbulnya kenakalan remaja. Dengan hubungan emosional yang terjalin antara orang tua dan anak, hal inipun akan berpengaruh terhadap kecerdasan dan karakter dari anak tersebut.

Seperti yang dikemukakan oleh Dagun, save (2013) mengatakan bahwa anak laki-laki dalam perkembangannya menuju dewasa juga dipengaruhi situasi keluarga. Tergantung pada siapakah yang paling berperan dalam keluarga, ibu atau ayah. Bila posisi ibu lebih dominan maka hal itu dapat menyebabkan si anak menganggap ayahnya bukan model panutannya. Situasi semacam ini bagi seorang anak laki-laki akan mengakibatkan kurang memperhatikan sikap sebagai seorang laki-laki. Tetapi bila dalam keluarga yang berperan dominan adalah ayah, maka anak akan mengganggap ayahnya sebagai tokoh panutan.

Dari pernyataan Dagun tersebut, dapat disimpulkan bahwa kedekatan anak dengan orang tua akan menyebabkan orang tua mampu menjadi seorang figur yang dapat menjadi

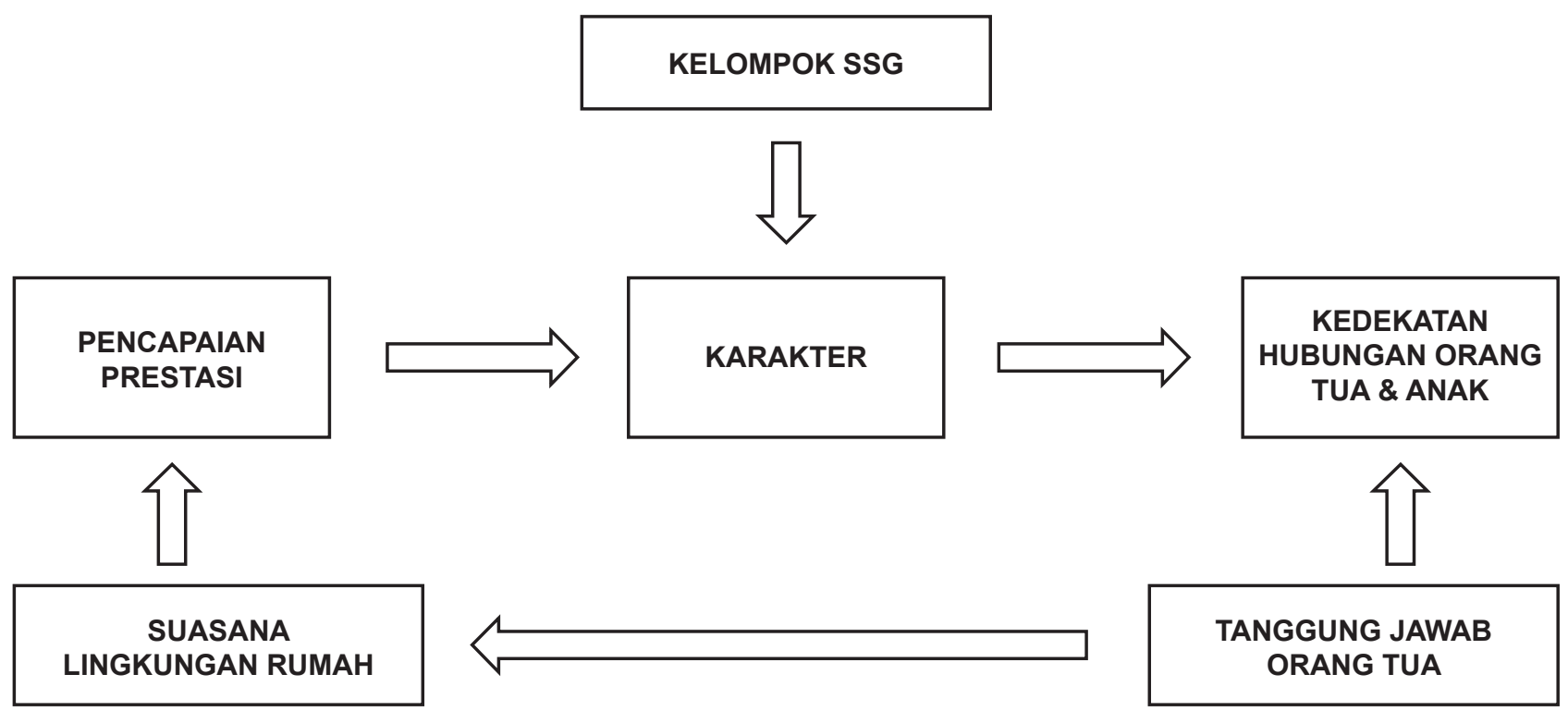


panutan bagi seorang anak. Hubungan antara anak dan orang tua yang baik, akan menyebabkan anak merasa nyaman dan mampu menyelesaikan segala permasalahan-permasalahan yang dihadapinya, baik dengan teman bermain, lingkungan sekolah, maupun masyarakat disekitar tempat tinggalnya yang mampu membuat perasaan anak menjadi tenang. Jika perasaan seperti itu telah masuk kedalam relung hati anak, saat itulah anak akan memahami bahwa keluarga merupakan tempat mencurahkan segala perasaan, baik bahagia, senang, maupun sedih. Hal ini sesuai dengan ajaran Hindu yang menyatakan mengenai peran orang tua dalam membangun kehidupan anak yang berkualitas, dimana didalam Canakya niti sastra Bab I sloka 12 disebutkan:

Utsave vyasane prapte

Durbhikse satru samkate

Raja dvare smasane ca

yastisthati sa bandhavah

Artinya:

Di dalam perayaan/pesta, didalam kedukaan, di waktu sedang kekurangan makanan, di waktu musuh menyerang, didalam sidang raja dan ditempat-tempat pembakaran mayat (smasane) atau kuburan, kalau seseorang selalu bersama kita, pada saat-saat seperti itu dialah keluarga kita yang sebenarnya.

(Canakya niti sastra sloka Bab I. 12)

Seloka tersebut menyiratkan bahwa kedekatan orang tua dengan anak yang tinggi akan menyebabkan anak merasa orang tua, akan selalu ada dikala anak merasa bahagia maupun menderita. Orang tua akan selalu ada disaat anak-anaknya sakit, dan akan menjadi orang pertama yang merasa bahagia ketika anakanaknya berbahagia.

\section{Tanggung Jawab Orang Tua}

Sedari anak didalam kandungan sampai anak menikah, orang tua memiliki tanggung jawab yang sangat besar. Baik untuk mendidik, membina, memberikan makan, menjaga kesehatan anak, dan memberikan anak pendidikan yang layak. Melalui pendidikan yang diberikan, diharapkan anak akan memiliki kemampuan untuk memberdayakan dirinya.
Dalam mendorong kemampuan anak untuk pemberdayaan dirinya. Menurut Aunurrahman (2011), orang tua memiliki tanggung jawab dalam upaya pemberdayaan diri melalui proses belajar yaitu: (i) mengetahui kekuatan dan keterbatasan diri, (ii) meningkatkan rasa percaya diri (iii) dapat meningkatkan kemampuan menghargai diri dan orang lain, (iv) meningkatkan kemandirian dan inisiatif untuk memulai perubahan, (v) meningkatkan komitmen dan tanggung jawab, (vi) meningkatkan motivasi internal, (vii) meningkatkan kemampuan mengatasi masalah secara kreatif dan positif, (viii) meningkatkan kemampuan untuk melaksanakana tugas secara professional (ix) mendorong kemampuan pengendalian diri dan tidak mudah menyalahkan orang lain, $(\mathrm{x})$ meningkatkan kemampuan membina hubungan interpersonal dengan baik, (xi) meningkatkan kemampuan beradaptasi dengan lingkungan.

Tanggung jawab orang tua seperti yang termuat diatas, sangat sesuai dengan ajaran Hindu. Dimana didalam ajaran agama Hindu dikatakan mengenai tanggung jawab orang tua, yang termuat didalam Niti sastra VIII.3 yang berbunyi:

Ring rat pitre ngaranya panca-widha sang matulung urip I kalaning bhaya Mwag sang nitya maweh bhinojana taman wales I sahananing huripnira

Lawan sang pangupadhyayan bapa ngarannya

sira sang anangaskare kita

Tan waktan sang ametwaken ri kita panca-

widhi bapa ngaranya kawruhi

\section{Artinya:}

Di dunia ini yang di sebut bapak ada lima, yaitu: orang yang menolong jiwamu waktu kamu dalam bahaya, orang yang member makan selama kamu hidup, dengan tiada menerima balasan apa-apa, orang yang mengajar kamu, orang yang menyucikan dirimu, dan tentu saja orang yang menyebabkan kamu lahir, ingatingatlah semua itu

(Niti sastra VIII.3) 
Sloka tersebut menjelaskan bahwa orang tua terutama bapak, memiliki tugas dan tanggung jawab membela anak-anaknya jika mendapatkan bahaya dan mengindari sang anak dari serangan penyakit, oleh karena itu orang tua memiliki tugas mengusahakan memberi makanan yang sehat dan bergizi. Bahkan bagi keluarga yang mengalami kesulitan ekonomi, orang tua rela berkorban untuk tidak makan, namun mendahulukan anak-anaknya untuk mendapatkan makanan yang layak, tanpa berharap balasan dari pemberian yang dilakukan kepada darah dagingnya sendiri. Selain itu pula, tugas dan tanggung jawab orang tua adalah sebagai pendidik.

Orang tua merupakan pendidik pertama dan utama didalam keluarga. Orang tualah yang mengajari kita berbicara, belajar merangkak, berdiri, berjalan, dan menyekolahkan kita . Orang tua yang mengajarkan sikap dan budi pekerti yang luhur, dan memberikan dasardasar pengetahuan bagi kebahagiaan dan kesejahteraan anak-anaknya kelak. Selain itu, tugas orang tua lainnya adalah menyucikan atma dan stula sariranya. Dengan cara melakukan upacara megedong-gedongan saat bayi masih didalam kandungan, kepus pungsed, tutug kambuhan, telu bulanan, otonan, menek bajang, mepandes, pawiwahan. Dan terakhir karena orang tualah yang menyebabkan seseorang itu bisa lahir ke dunia.

\section{Suasana d Ilingkungan Rumah}

Lingkungan terkecil dalam suatu sistem masyarakat adalah keluarga, dimana tempat seorang anak dilahirka, dididik dan dibina. Di dalam keluarga, seorang anak akan berinteraksi dengan ayah, ibu, kakak, adik, kakek, nenek, maupun paman dan bibinya. Seorang anak akan belajar mengenai pola tingkah laku dan kebiasaan yang terjadi di lingkungan rumahnya. Bila dilingkungan keluarganya terbiasa mengucapkan kata-kata yang sopan dan halus, maka anak lambat laun akan belajar bagaimana cara bertutur kata yang sopan. Namun jika seorang anak sering kali disuguhkan kekerasan yang terjadi di dalam rumah tangga, maka lambat laun anakpun akan memiliki sikap keras yang ia pelajari dari lingkungan disekelilingnya. Bila lingkungan keluarganya, adalah keluarga yang belajar, maka dia juga cenderung belajar. Oleh karena itu, orangtua memegang peranan penting untuk mengorganisir kondisi belajar di keluarga, untuk menunjang prestasi belajar anak. Munirwan Umar (2015)

Pada fase awal perkembangan moral anak menurut Suasthi \& suastawa (2014) menyatakan lebih banyak meniru sikap dan perilaku orangorang terdekat baik orang tua, saudara kandung maupun pengasuhnya. Agar tidak membingungkan si anak, maka perlu adanya kesepakatan bersama untuk selalu mengedepankan perilaku keagamaan. Seperti mengajarkan nilai-nilai kejujuran, maka semua anggota keluarga selalu komit mengatakan apa adanya, tanpa ada yang ditutupi. Menanamkan nilai toleransi atau kebersamaan, misalnya: makan malam bersama keluarga, ataupun melakukan persembahyangan dirumah secara bersama-sama.

Didalam ajaran agama Hindu, sangat ditekankan untuk membentuk suatu lingkungan yang baik sebagai tempat seorang anak akan tumbuh dan berkembang. Seperti yang tercantum di dalam yajurveda VIII.51 dan di Atharvaveda VI.120.3 yang berbunyi:

Yajurveda VIII.51

Iha ratir iha ramadhvam

Iha dhrtir iha svadhrtih

\section{Artinya:}

Semoga terdapat cinta kasih di dalam keluarga. Semoga semuanya hidup dengan penuh kasih sayang di sini. Semoga terdapat kesabaran, kemantapan dan kepercayaan diri. (Titib, 1998)

Atharvaveda VI.120.3

Yatra sudardah sukrto madanti

Vihaya rogam tanvah svayah

\section{Artinya:}

Jadikan rumahmu seperti sorga, tempat berkumpulnya pikiran-pikiran yang mulia, kebajikan dan kebahagiaan berkumpul di rumahmu itu. (Titib, 1998)

Dari pemaparan kedua seloka tersebut, dapat ditarik suatu kesimpulan bahwa didalam sebuah keluarga sangat ditekankan untuk 
mengembangkan prinsip cinta kasih. Dengan adanya cinta kasih yang terjalin didalam keluarga, maka akan menimbulkan perasaan sabar ketika terdapat perselisihan, kemantapan dan kepercayaan diri dalam menyelesaikan segala permasalahan yang ada. Dan jika didalam sebuah rumah telah dipenuhi dengan prinsipprinsip cinta kasih, maka suasana rumah akan menjadi damai, tenang dan nyaman, layaknya sebuah surga didalam kehidupan duniawi. Karena kesabaran dan cinta kasih yang terdapat didalam keluarga, akan menimbulkan pikiranpikiran yang mulia sehingga kebijaksanaan akan berada ditempat tersebut, dengan kebijaksanaan yang ada akan dapat menghasilkan kebahagiaan.

\section{Pencapaian Prestasi}

Sebagai orang tua, melihat anak memiliki prestasi tentu menjadi kebanggan tersendiri. Orang tua merasa telah berhasil dalam mendidik anak jika meihat anak-anaknya mencapai prestasi yang diharapkan. Untuk itu sebagai orang tua menurut Aunurrahman (2011), orang tua dapat membantu mengembangkan kemampuan menumbuh kembangkan motivasi diri anak melalui: a) Mengajarkan anak mengharapkan keberhasilan, b) Menyediakan kesempatan bagi anak untuk menguasai lingkungannya, c) Memberikan pendidikan yang relevan dengan gaya belajar anak, d) Mengajarkan anak untuk menghargai sikap tidak mudah menyerah, e) Mengajarkan anak pentingnya menghadapi dan mengatasi kegagalan.

Didalam ajaran Hindupun dijelaskan bagaimana peran orang tua di dalam mencapai prestasi anak. Seperti yang dijabarkan didalam Niti Sastra bab IV, Sloka I dikatakan:

Sanghyang candra teranggana pinaka dipa memandangi rikalaning wengi,

Sanghyang surya sedeng prabhasa maka dipa memandangi ri bhumi manadala

Widya castra sudharma dipanikang tribhuwana sumene prabhaswara

Yan ring putra suputra sadhu gunawan memandangi kula wandhu wandawa

\section{Artinya:}

Bulan dan bintang memberi penerangan di waktu malam, matahari bersinar menerangi bhumi, ilmu pengetahuan, pelajaran, peraturan-peraturan yang baik menerangi tiga jagat dengan sempurna, Putra yang baik, saleh dan pandai membahagiakan kaum keluarganya

Dari seloka tersebut, sangat jelas dikatakan bahwa dalam menjadikan seorang anak menjadi baik, dan saleh, orang tua memiliki kewajiban untuk memberikan pengetahuan-pengetahuan dan atuan-aturan di dalam ajaran Hindu, sehingga anak menjalankan kehidupannya tidak salah arah dan langkah. Dengan harapan anak akan menjadi anak yang suputra yang akan selalu dapat memberikan kebahagiaan kepada keluarganya

\section{PENUTUP}

Dalam penyebaran pendidikan agama Hindu guna membentuk karakter anak pada kelompok SSG Praya, Kabupaten Lombok Tengah di dalam keluarga dilakukan dengan cara: 1) menyanyikan lagu-lagu suci keagamaan (dharma Gita). 2) mendengarkan dan bergiliran dalam mewacanakan ajara-ajaran suci agama (dharma wacana).3) berdiskusi secara berkala membahas inti sari pengetahuan-pengetahuan rohani (dharma Tula). 4) memberikan persembahan dengan tulus iklas (dharma sadana). 5) mengunjungi tempat-tempat suci (dharma yatra). 6) serta menjalin hubungan yang baik dengan sesame sehingga memperoleh kedamaian (dharma santih).

Pola yang diterapkan oleh kelompok SSG dalam membentuk karakter anak di dalam keluarga dengan cara melakukan pendekatan hubungan antara orang tua dan anak, melaksanakan tanggung jawab orang tua terhadap anak, membuat lingkungan rumah yang nyaman dan memantau tumbuh kembang anak agar prestasi anak dapat tercapai dengan baik 


\section{DAFTAR PUSTAKA}

Aryanatha, I Nengah. 2017. Tirtayatra sebagai Bentuk Wisata Religi Masyarakat Hindu di Bali. Jurnal Pariwisata dan Budaya vol 2 no 2 http://ejournal.ihdn.ac.id/index.php/PB/article/ view/843/699 diakses tanggal 3 Juli 2019

Aunurrahman. 2011. Belajar dan pembelajaran. Bandung: Alfabeta

Dagun, M. Save. 2013. Psikologi Keluarga. Jakarta: Rineka cipta

Dharmayasa, I Made. 1995. Canakya niti sastra. Denpasar: yayasan dharma naradha

Ida Bagus Sudirga. 2017. Peranan Dharmagita Dalam Meningkatkan Sradha Dan Bhakti Siswa Hindu. Vidya Samhita Jurnal Penelitian Agama, III (1). http://ejournal.ihdn.ac.id/index.php/ vs/article/download/331/293 diakses tangal 3 Juli 2019

Juwita Br Meliala, I Made Sujana, Anak Agung Made Putra Arsana 2018. Pola Pembelajaran NilaiNilai Etika Agama Hindu Pada Peserta Didik Di Pasraman Raksa Bhuana Medan Vol 2 No 1 http://ejournal.ihdn.ac.id/index.php/JPAH/article /view/455/375 diakses tanggal 3 Juli 2019

Munirwan Umar. 2015. Peranan Orang Tua Dalam Peningkatan Prestasi Belajar Anak Jurnal Ilmiah Edukasi Vol 1, Nomor 1, https://jurnal.ar-raniry.ac.id/index.php/cobaBK/article/ view/315/291 diakses tanggal 3 Juli 2019

Suasthi dan Suastawa. 2014. Psikologi Agama. Denpasar: Putra Jaya

Syamsuar dan Reflianto. 2018. Pendidikan Dan Tantangan Pembelajaran Berbasis Teknologi Informasi Di Era Revolusi Industri 4.0 Universitas Negeri Malang Vol 6, No 2 http:// ejournal.unp.ac.id/index.php/etech/article/view/101343 diakses tangal 3 Juli 2019

Titib, I Made. 1998. Veda Sabda Suci. Surabaya: Paramita 